\title{
Milk thistle and olive extract: mediterranean cytoprotection
}

\author{
R. Di Caprio1, G. Monfrecola1, A. Balato², G. Caiazzo1, F. Gasparri'3, S. Lembo4
}

1Department of Clinical Medicine and Surgery, University of Naples Federico II, Italy

2Department of Advanced Biomedical Sciences, University of Naples Federico II, Italy 3Department of Pharmacy (DIFARMA), University of Salerno, Italy

${ }^{4}$ Department of Medicine, Surgery and Dentistry, Scuola Medica Salernitana, University of Salerno, Italy

INTRODUCTION:

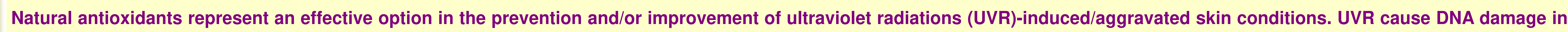

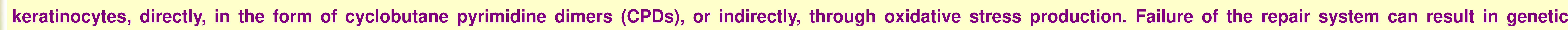
mutations primarily responsible for the initiation of non melanoma skin cancers (NMSCs).

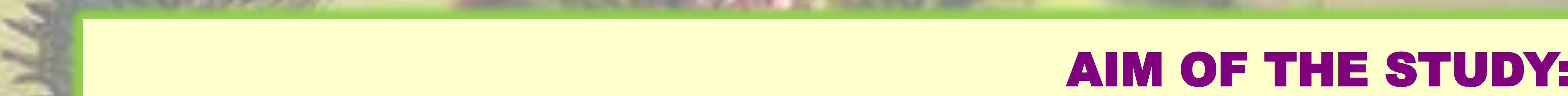

To evaluate, in vitro, the protective effect of milk thistle and olive purified extracts on cultured keratinocytes, after solar simulator radiation (SSR).

\section{MATERIALS AND METHODS:}

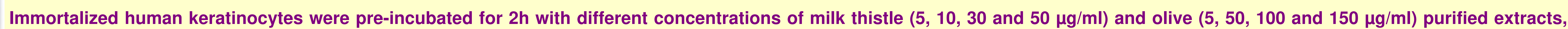

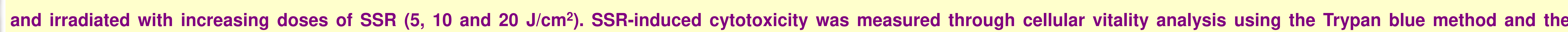

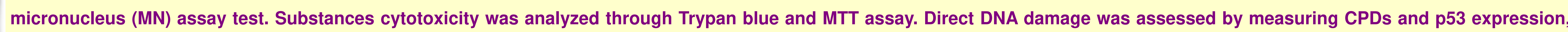

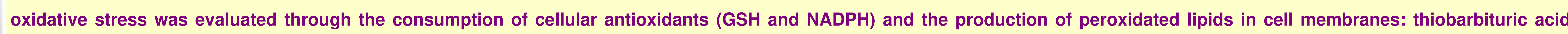
reacting substances (TBARs).



SSR 10 and $20 \mathrm{~J} / \mathrm{cm}^{2}$ slightly decreased cell viability, allowing a good survival rate to analyse the stimulatory effects induced
SSR $20 \mathrm{~J} / \mathrm{cm}^{2}$ significantly increased the number of MN-positive cells, considered as a marker of the direct DNA-damage (e).

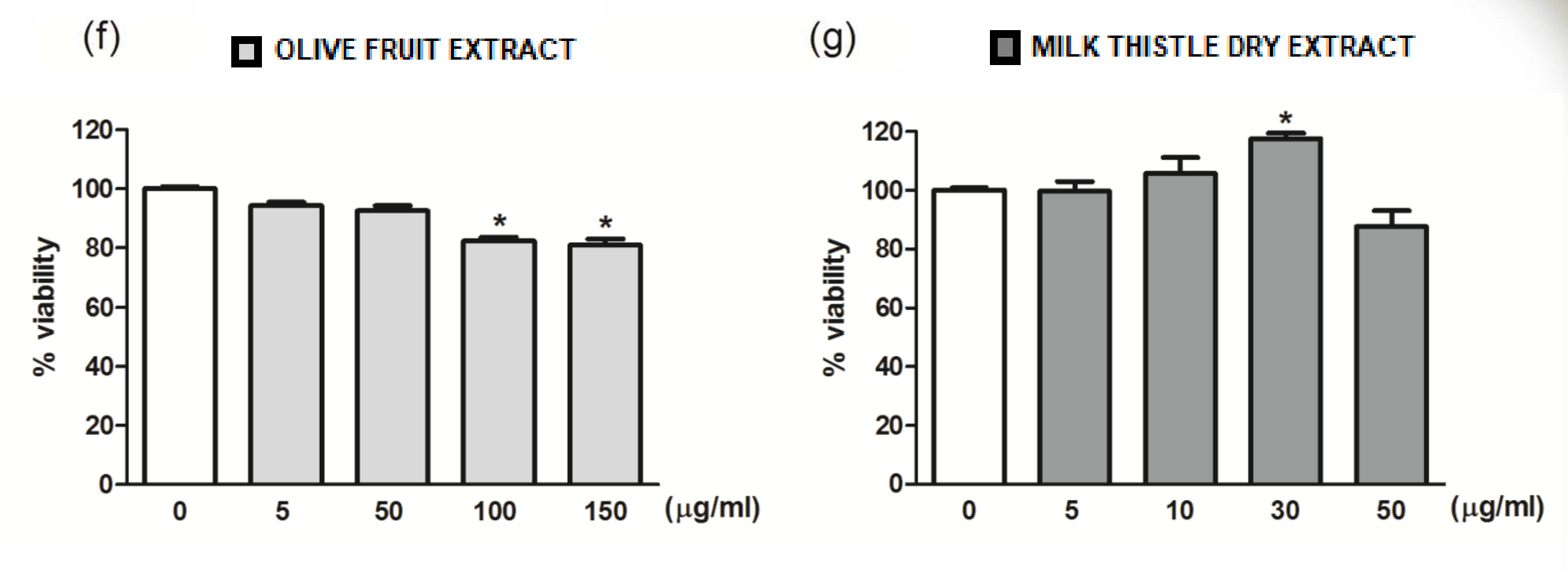
The highest olive extract tested concentrations $(100$ e $150 \mu \mathrm{g} / \mathrm{ml})$ slightly
affect cell viability (f) whereas milk thistle dry extract $30 \mu \mathrm{g} / \mathrm{ml}$ increased it (g). Cellular viability rate and statistical significance were determined with respect to the $100 \%$ viability of untreated control cells $\left(^{*}\right)$

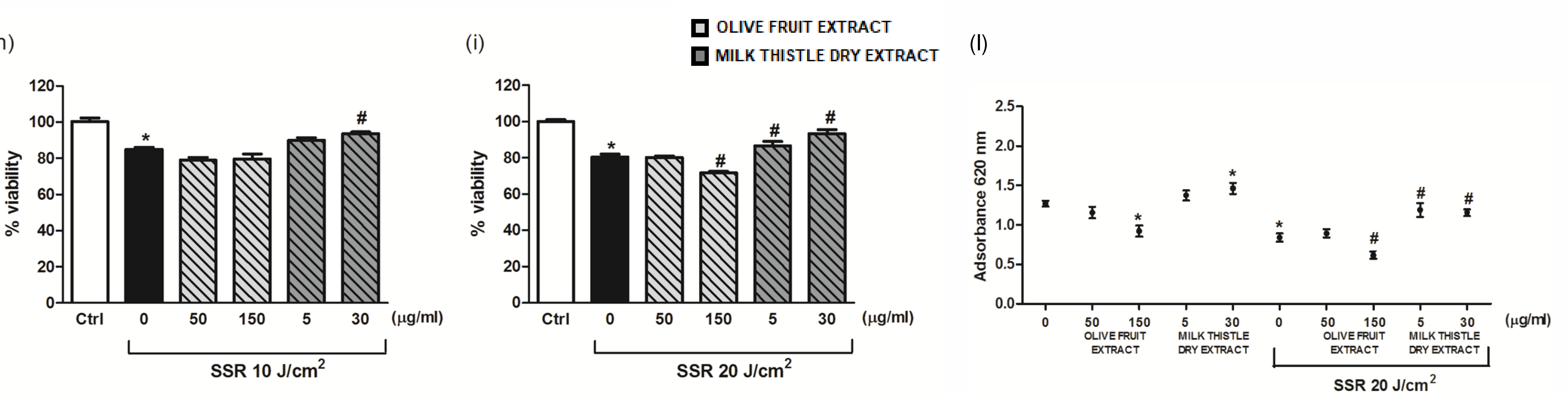

Pre-treatment with milk thistle dry extract (5 e $30 \mu \mathrm{g} / \mathrm{ml})$, but not with olive extract ( 100 e $150 \mu \mathrm{g} / \mathrm{ml}$ ), obtained with Trypan blue method were confirmed through the MTT assay (I).

SSR-induced cytotoxicity and statistical significance were determined with respect to the $100 \%$ viability of unirradiated control cells (*); substances ability to modulate SSR-induced cytotoxicity was compared to irradiated cells (\#).

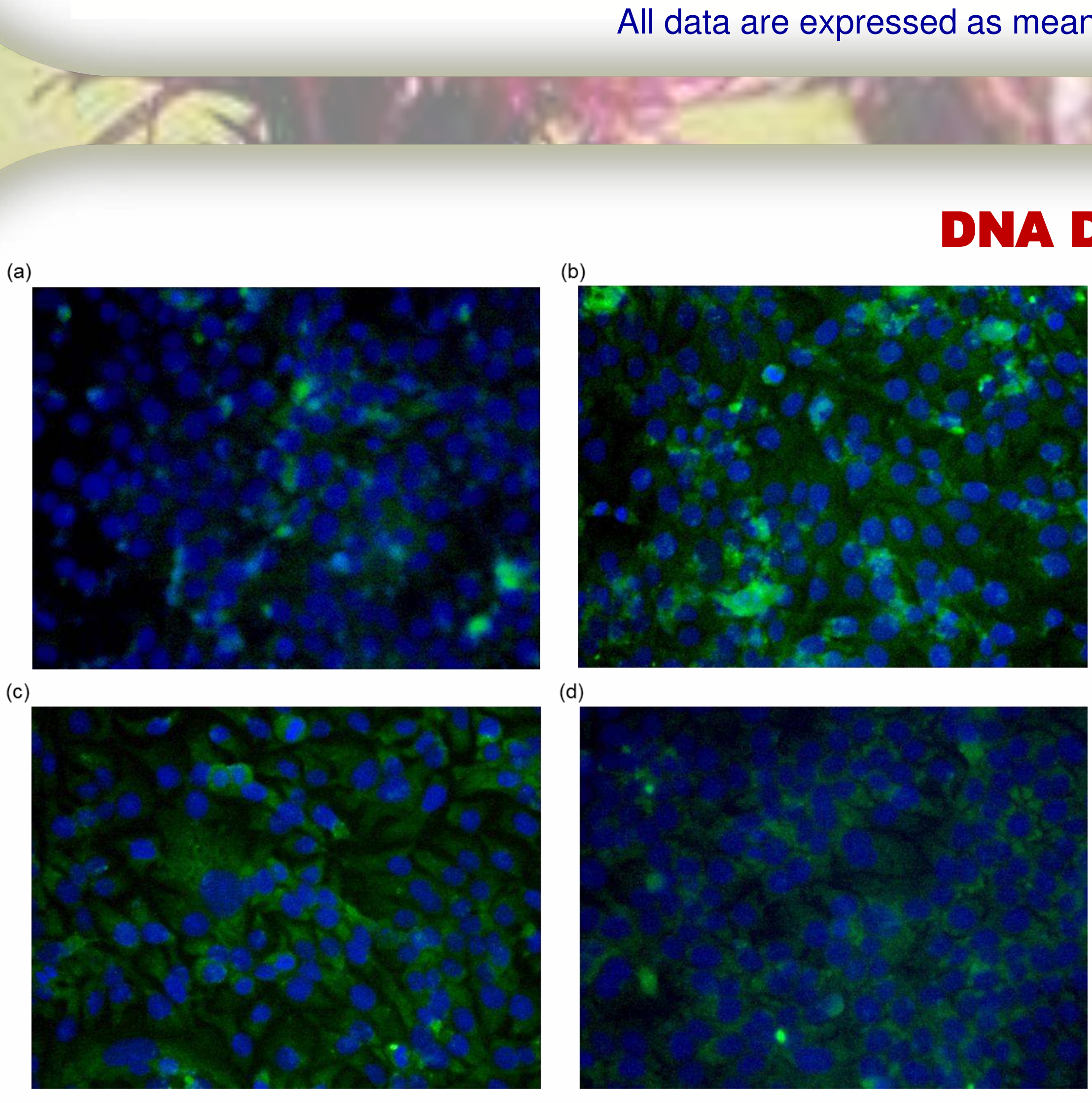

SSR $20 \mathrm{~J} / \mathrm{cm}^{2}$ resulted in higher number of CPD levels (b) compared to control cells (a). Pre-treatment with milk thist dry extract $(30 \mu \mathrm{g} / \mathrm{ml})(\mathrm{d})$, but not with olive extract $(150 \mu \mathrm{g} / \mathrm{ml}$
Na damage
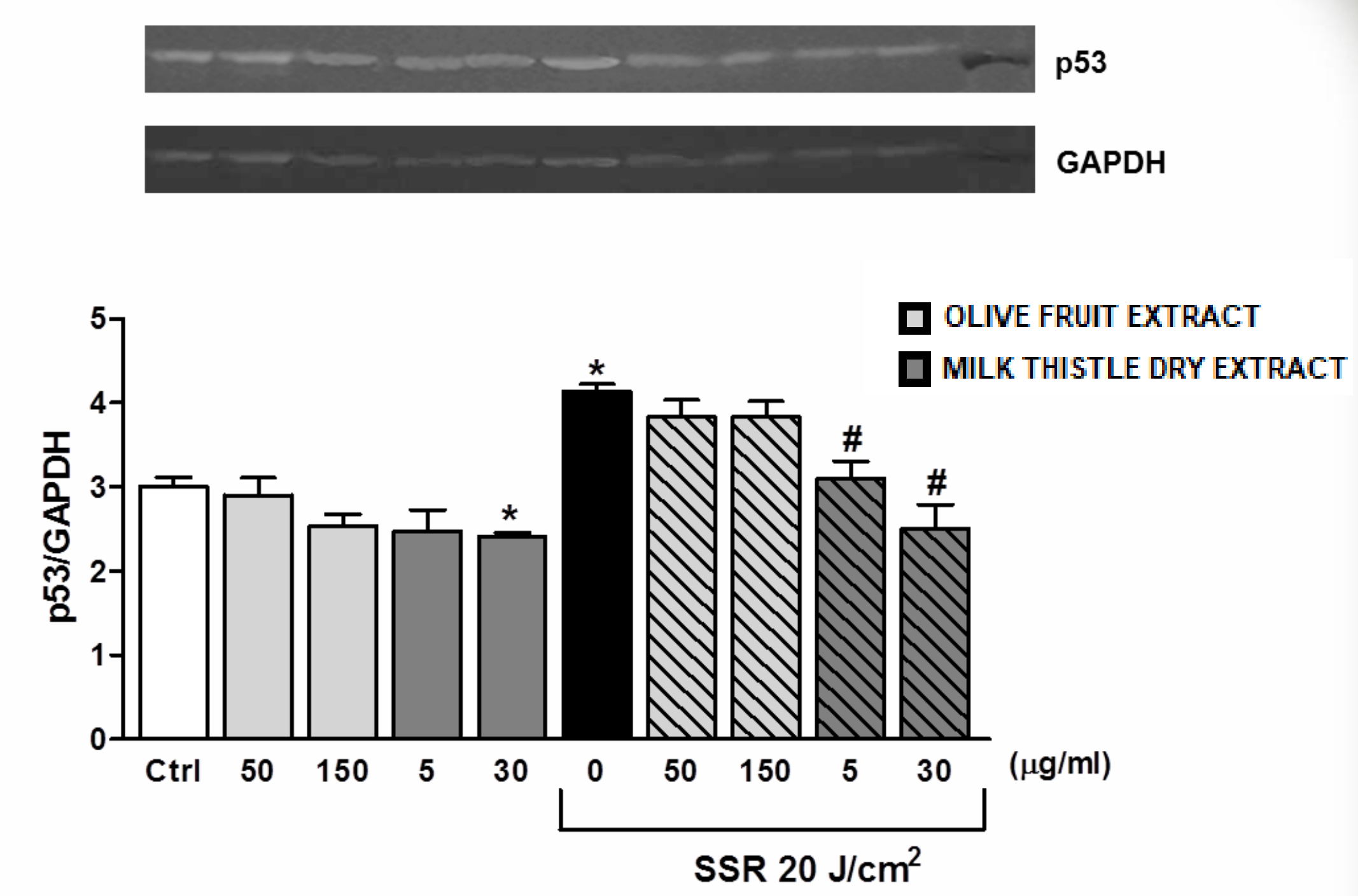

SSR $20 \mathrm{~J} / \mathrm{cm}^{2}$ significantly increased p53 expression compared to control cells. Only pre-treatment with milk thistle dry extract was able to down-regulate it, also when used in basal conditions.

Data were compared to control cells (*) and to SSR-irradiated cells (\#).

Data are expressed as mean $\pm \mathrm{SD}$ of three independent experiments, each performed in triplicate. Student's $\mathrm{t}$-test was used to calculate
significant differences. $\left({ }^{*} \mathrm{P}<0.05 ; \# \mathrm{P}<0.05\right)$.

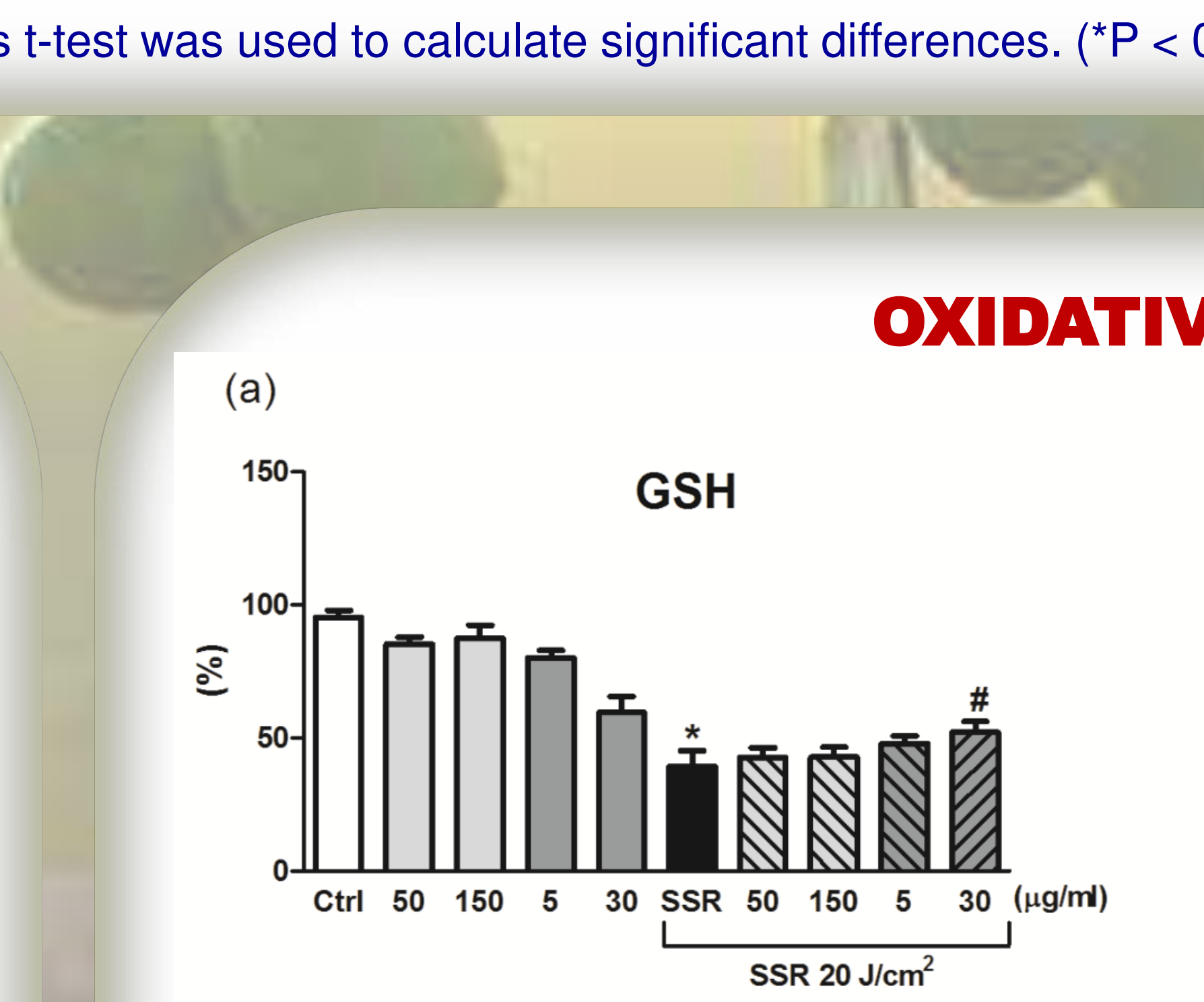

Olive and, with minor extent, milk thistle extract, significantly reduced SSR-induced cellular GSH (a) and NADPH (b) depletion.

Only olive extract was able to reduce SSRinduced TBAR increases (c).

Data were compared to control cells $\left(^{*}\right)$ and to SSR-irradiated cells (\#)
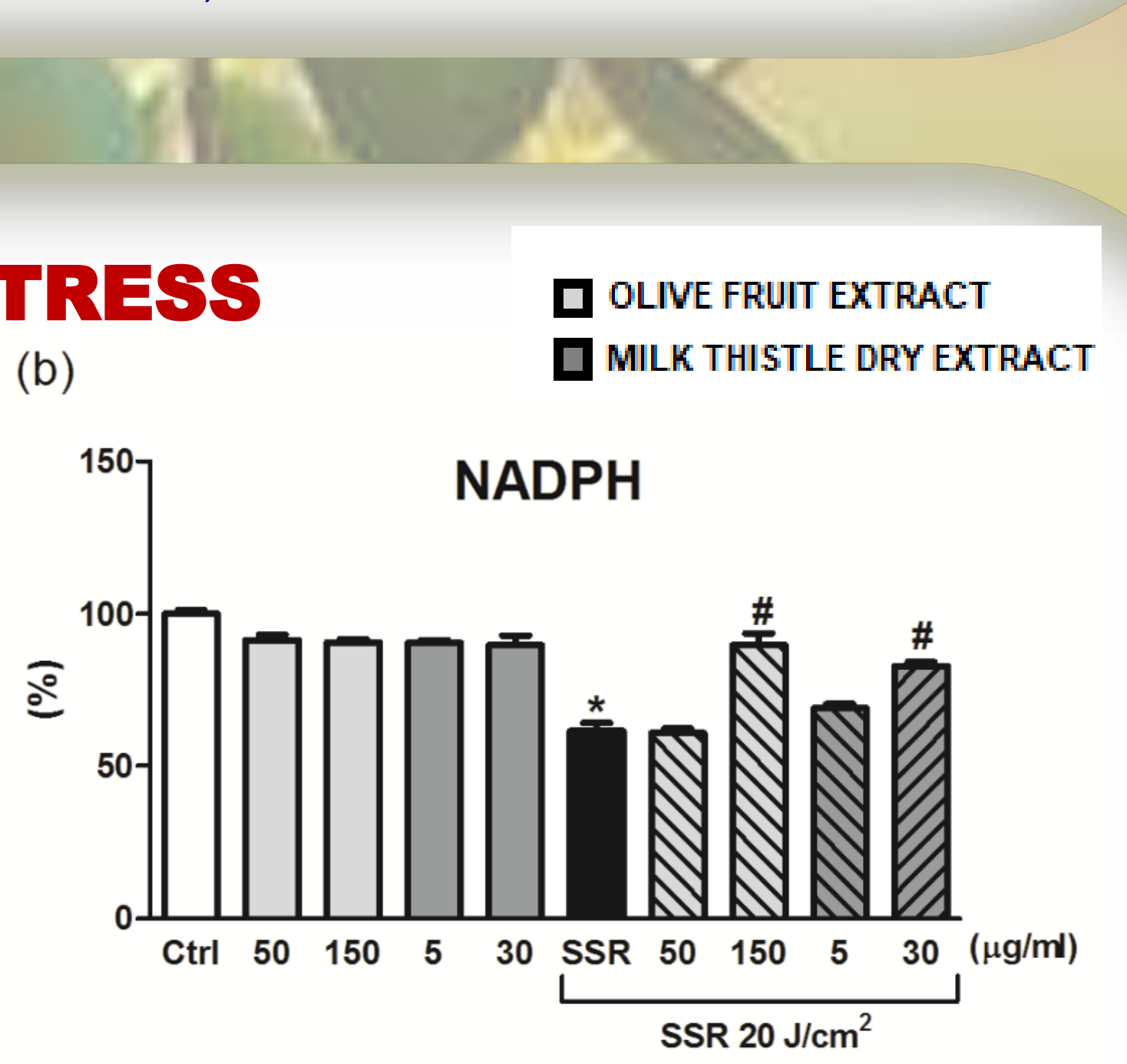

TBARs

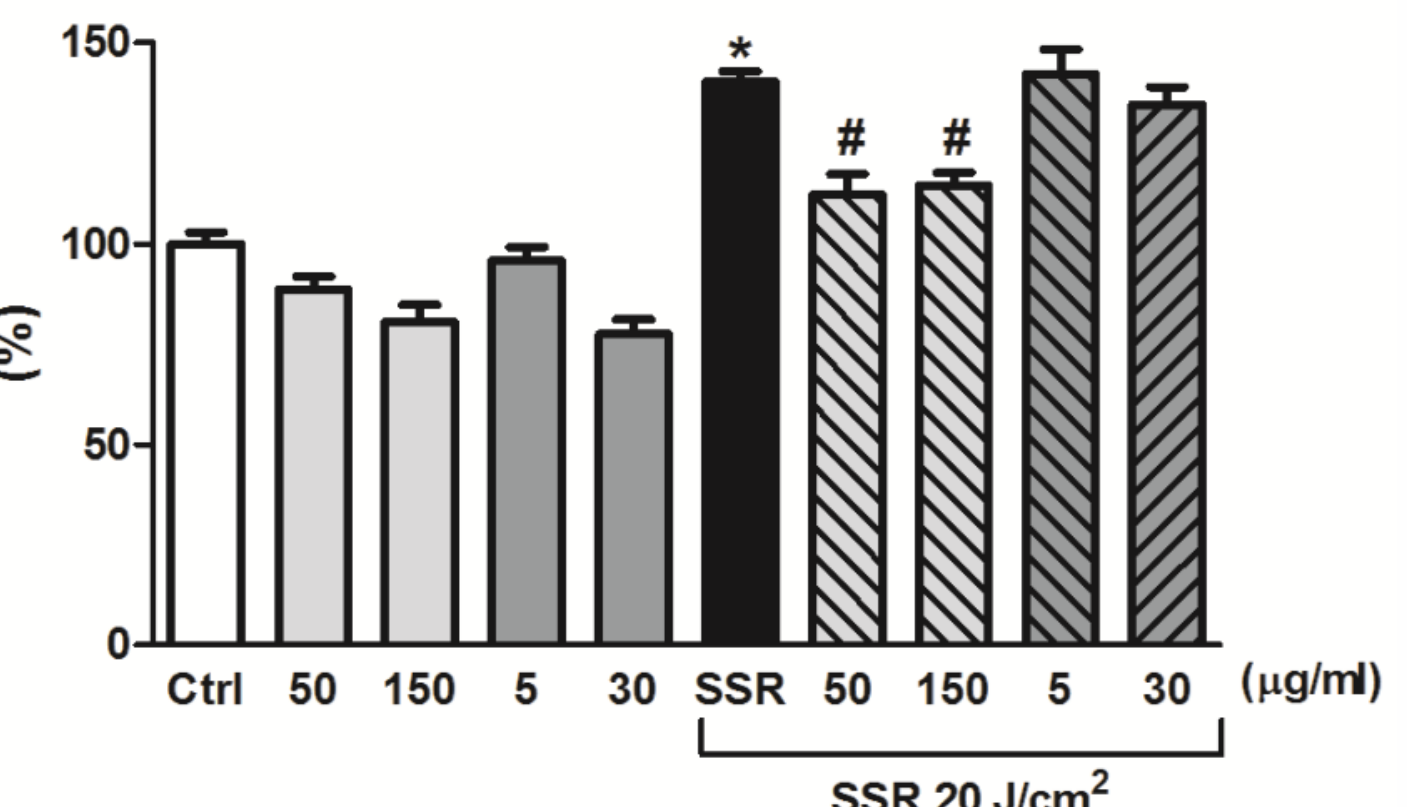

All data are expressed as mean $\pm \mathrm{SD}$ of three independent experiments, each performed in 